\title{
Effect of air pollution on diabetes and cardiovascular diseases in São Paulo, Brazil
}

\author{
M.A. Pereira Filho1 ${ }^{1}$, L.A.A. Pereira ${ }^{1,2,3}$, F.F. Arbex¹, M. Arbex ${ }^{1}$, G.M. Conceição ${ }^{1}$, \\ U.P. Santos ${ }^{3,4}$, A.C. Lopes ${ }^{1}$, P.H.N. Saldiva ${ }^{3}$, A.L.F. Braga ${ }^{2,3,5}$ and S. Cendon ${ }^{1}$
}

${ }^{1}$ Programa de Pós-graduação em Clínica Médica, Escola Paulista de Medicina, Universidade Federal de São Paulo, São Paulo, SP, Brasil

2Programa de Pós-graduação em Saúde Coletiva, Universidade Católica de Santos, Santos, SP, Brasil

${ }^{3}$ Laboratório de Poluição Atmosférica Experimental, ${ }^{4}$ Divisão de Pneumologia do Instituto do Coração, Faculdade de Medicina, Universidade de São Paulo, São Paulo, SP, Brasil

${ }^{5}$ Programa de Pediatria Ambiental, Faculdade de Medicina, Universidade de Santo Amaro, Santo Amaro, SP, Brasil

Correspondence to: L.A.A. Pereira, Rua Pedro de Toledo, 920, 04039-002 São Paulo, SP, Brasil

E-mail: luiz.aa.pereira@uol.com.br

Type 2 diabetes increases the risk of cardiovascular mortality and these patients, even without previous myocardial infarction, run the risk of fatal coronary heart disease similar to non-diabetic patients surviving myocardial infarction. There is evidence showing that particulate matter air pollution is associated with increases in cardiopulmonary morbidity and mortality. The present study was carried out to evaluate the effect of diabetes mellitus on the association of air pollution with cardiovascular emergency room visits in a tertiary referral hospital in the city of São Paulo. Using a time-series approach, and adopting generalized linear Poisson regression models, we assessed the effect of daily variations in $\mathrm{PM}_{10}, \mathrm{CO}, \mathrm{NO}_{2}, \mathrm{SO}_{2}$, and $\mathrm{O}_{3}$ on the daily number of emergency room visits for cardiovascular diseases in diabetic and non-diabetic patients from 2001 to 2003 . A semi-parametric smoother (natural spline) was adopted to control long-term trends, linear term seasonal usage and weather variables. In this period, 45,000 cardiovascular emergency room visits were registered. The observed increase in interquartile range within the 2-day moving average of $8.0 \mu \mathrm{g} / \mathrm{m}^{3} \mathrm{SO}_{2}$ was associated with $7.0 \%(95 \% \mathrm{Cl}: 4.0-11.0)$ and $20.0 \%(95 \% \mathrm{Cl}: 5.0-44.0)$ increases in cardiovascular disease emergency room visits by non-diabetic and diabetic groups, respectively. These data indicate that air pollution causes an increase of cardiovascular emergency room visits, and that diabetic patients are extremely susceptible to the adverse effects of air pollution on their health conditions.

Key words: Cardiovascular diseases; Diabetes; Air pollution; Emergency room visits; Time-series study

Research supported by Disciplina de Clínica Médica, Departamento de Medicina, and Laboratório de Poluição Atmosférica Experimental, Faculdade de Medicina, USP (FMUSP). Publication supported by FAPESP.

Received April 27, 2007. Accepted April 17, 2008

\section{Introduction}

Evidence obtained from both experimental and epidemiological studies indicates that air pollution may have adverse effects on both respiratory and cardiovascular systems, even though the mechanisms of cardiovascular damage are not completely known (1-5).

Epidemiological approaches for evaluating the asso- ciation between cardiovascular mortality and air pollution have shown increased risk of fatal events due to increased concentrations of air pollution $(1,3)$.

In São Paulo, Brazil, a time-series study carried out by Lin and colleagues (6) highlights the relationship between air pollutants and ischemic cardiac diseases such as angina and acute myocardial infarction, in a representative cardiovascular emergency center. An interquartile range 
increase in $\mathrm{CO}$ was associated with an increase of $6.4 \%$ $(95 \% \mathrm{Cl}: 0.7-12.1)$ in daily angina or acute myocardial infarction emergency room (ER) visits. de Paula Santos and colleagues (7), evaluating the effects of air pollution in the city of São Paulo vehicular traffic control stations found that an interquartile range increase in $\mathrm{CO}(1.1 \mathrm{ppm})$ was associated with increases of $2.6 \mathrm{mmHg}(95 \% \mathrm{Cl}: 1.0-4.2)$, $1.8 \mathrm{mmHg}(95 \% \mathrm{Cl}: 0.8-2.8)$, and $2.4 \mathrm{mmHg}(95 \% \mathrm{Cl}: 1.1-$ 3.6) in systolic, diastolic, and 24-h mean ambulatory blood pressure measurements, respectively. It was also shown that $\mathrm{SO}_{2}$ had relevant effects on blood pressure as well. An interquartile range increase in $\mathrm{SO}_{2}\left(9.6 \mu \mathrm{g} / \mathrm{m}^{3}\right)$ was negatively associated with the standard deviation of normal RR intervals $-7.93 \mathrm{~ms}(95 \% \mathrm{Cl}:-15.3,-0.6)$, showing a reduction in the heart rate variability.

Other diseases can modify the effect of air pollutants on cardiovascular problems. Zanobetti and Schwartz (8) observed that, among diabetics, the risk of hospital admissions for heart diseases is 2-fold greater than that observed for non-diabetic people. The authors discussed whether both diabetes and airborne particles have been associated with decreased heart rate variability, increased thrombosis risk factors and increases in systemic markers of inflammation.

Diabetes is almost of epidemic dimensions in the world where air pollution increases annually and both factors affect the cardiovascular system. Hence, this study was carried out to evaluate the association between air pollution and cardiovascular ER visits in subjects with and without diabetes, in the city of São Paulo, located by the following coordenates: latitude $23^{\circ} 34^{\prime}$ South, longitude $46^{\circ} 38^{\prime}$ West.

\section{Material and Methods}

This is an ecological time-series study using secondary health data from the São Paulo Hospital of the Medical School of the Federal University of São Paulo, a tertiary referral teaching hospital in São Paulo's regional health system, with 600 beds and emergency service care for more than 300,000 patients annually. From January 2001 to July 2003, daily records of hypertension and cardiac ischemic disease were selected from ER visits using the International Classification of Diseases (ICD-10: I10-I25) (9) of adults over 18 years of age, with and without diabetes (ICD-10: E10-E15).

São Paulo State Sanitary Agency (CETESB) provided daily records of $\mathrm{NO}_{2}, \mathrm{SO}_{2}, \mathrm{CO}, \mathrm{O}_{3}$, and $\mathrm{PM}_{10}$ for the same period. At that time, there were 13 monitoring stations distributed throughout the city although not all of them were then capable of measuring all pollutants in the air. We thus adopted the measurements from all stations to calculate the mean values per pollutant. These averages were then used as a citywide exposure status per pollutant, with the following characteristics: $\mathrm{CO}$, the measurement adopted was the highest 8-h moving average from five stations; $\mathrm{NO}_{2}$ and $\mathrm{O}_{3}$ concentrations were computed as the highest hourly average from four stations, and, for $\mathrm{PM}_{10}$ (12 stations) and $\mathrm{SO}_{2}$ (13 stations) the 24-h averages were adopted, according to the Brazilian Council for Environmental Standards (ConseIho Nacional do Meio-Ambiente, CONAMA). All pollutants were measured in the period from 1 am to $12 \mathrm{pm}$. Information on daily minimum temperature and relative humidity was obtained from the Institute of Astronomy and Geophysics of the University of São Paulo (IAG-USP).
Table 1. Descriptive analysis of the main variables included in Poisson regression models.

\begin{tabular}{lrrrr}
\hline Variables & \multicolumn{4}{c}{ Descriptive parameters } \\
\cline { 2 - 5 } & Mean \pm SEM & Minimum & IQR & Maximum \\
\hline CVD ER visits (visits/day) & & & & \\
$\quad$ Diabetics & $0.6 \pm 0.0$ & 0 & 1 & 5 \\
$\quad$ Non-diabetics & $16.8 \pm 0.3$ & 0 & 16 & 45 \\
Pollutants & & & & \\
$\quad \mathrm{CO}(\mathrm{ppm})$ & $2.7 \pm 0.0$ & 0.7 & 1.2 & 12.1 \\
$\mathrm{SO}$ & $13.8 \pm 0.2$ & 2.1 & 8.0 & 42.9 \\
$\mathrm{NO}_{2}\left(\mu \mathrm{g} / \mathrm{m}^{3}\right)$ & $114.8 \pm 1.6$ & 30.9 & 64.3 & 323.7 \\
$\mathrm{PM}_{10}\left(\mu \mathrm{g} / \mathrm{m}^{3}\right)$ & $50.0 \pm 0.7$ & 14.0 & 28.2 & 169.0 \\
$\quad \mathrm{O}_{3}\left(\mu \mathrm{g} / \mathrm{m}^{3}\right)$ & $94.4 \pm 1.4$ & 14.5 & 53.3 & 282.0 \\
$W_{\text {Weather factors }}$ & & & & \\
Minimum temperature $\left({ }^{\circ} \mathrm{C}\right)$ & $15.6 \pm 0.1$ & 3.7 & 5.1 & 21.8 \\
Relative humidity $(\%)$ & $79.1 \pm 0.3$ & 46.6 & 10.3 & 96.6 \\
\hline
\end{tabular}

$\mathrm{IQR}=$ interquartile range; CVD ER = number of cardiovascular disease emergency room visits.

\section{Statistical analysis}

The first step taken was towards describing each variable in terms of a valid number of observation means, median, quartiles, minimum, maximum values, and standard deviation.

The daily number of cardiovascular diseases (CVD) in diabetic and non-diabetic groups were considered as the dependent variables in generalized linear Poisson regression models (10) and the $\mathrm{PM}_{10}, \mathrm{CO}, \mathrm{NO}_{2}, \mathrm{SO}_{2}$, and $\mathrm{O}_{3}$ concentrations were considered as independent variables controlling weather variables. Natural cubic spline (11) was adopted for controlling long-time trends. For timetrend smoothing, we used 5 degrees of freedom. The number of degrees of freedom for the natural spline of time trend was chosen to minimize the autocorrelation between the residuals and Akaike Information Criterion (12). After adjustment for time- 
trend was done, no remaining serial correlation was found in the residuals and, therefore, the use of autoregressive terms was not necessary.

Since the effect of air pollution on morbidity/mortality is distributed over time, the number of events in a single day may be due to the exposure to air pollution not only on that day but over the preceding days as well. Therefore, to better investigate this pattern we included, in single pollutant models, their daily levels ranging from the concurrent day until 6 days before the ER visit. Cumulative effects were assessed with the inclusion of 2 to 7 days moving averages of pollutant daily concentrations. Based on a previous study by our group (6), we adopted linear terms (lags 0 and 1 ) to control both the effects of temperature and humidity on CVD ER visits.

We estimated percentage increases and $95 \% \mathrm{Cl}$ in CVD ER visits of diabetic and non-diabetic patients due to interquartile range increases in air pollutant concentrations.

The statistical packages used were SPSS-10.0 for Windows and Splus 4.5.

\section{Results}

During the period of study, 45,000 ER visits were registered due to cardiovascular diseases, of which 700 were registered due to cardiovascular diseases in diabetic patients.

Table 1 shows the descriptive analysis of the main variables included in the regression models. Daily mean of ER visits due to cardiovascular diseases in diabetic patients was almost thirty times smaller than that of nondiabetic patients. Additionally, during $50 \%$ of the periods analyzed there were no cardiovascular ER visits by diabetic patients. Air pollutant concentrations were below Brazilian air quality standards during $75 \%$ of the days studied. By any criteria, only sulfur dioxide, among the studied pollutants, did not exceed its standards at least once, and São Paulo cannot be considered a cold city as it has only a few days per year with temperatures below $10^{\circ} \mathrm{C}$.

Figure 1 shows temporal trends of air pollutants, temperature, humidity, and morbidity outcomes. Primary pollutants presented a seasonal pattern similar to those of

Figure 1. Time trends of air pollutants, weather variables and emergency room visit variables during the study period. CVD/ diab and CVD/nondiab are reported as daily number of cardiovascular disease emergency room visits by individuals with and without diabetes.

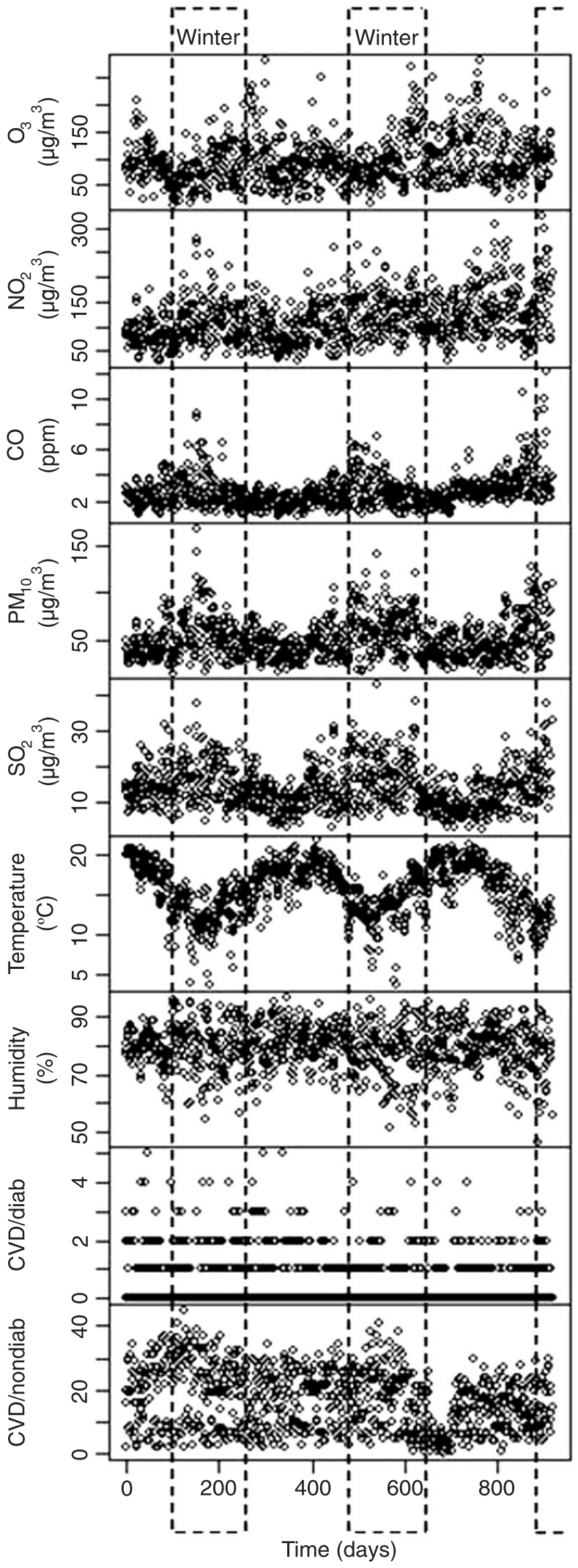

www.bjournal.com.br 
Table 2. Pearson correlation analysis of air pollutants and weather variables during the period analyzed.

\begin{tabular}{lccccccc}
\hline Variables & $\mathrm{O}_{3}$ & $\mathrm{NO}_{2}$ & $\mathrm{CO}$ & $\mathrm{PM}_{10}$ & $\mathrm{SO}_{2}$ & $\begin{array}{c}\text { Minimum } \\
\text { temperature }\end{array}$ & $\begin{array}{c}\text { Relative } \\
\text { humidity }\end{array}$ \\
\hline $\mathrm{O}_{3}$ & 1 & & & & & & \\
$\mathrm{NO}_{2}$ & $0.41^{*}$ & 1 & & & & & \\
$\mathrm{CO}$ & $0.07^{*}$ & $0.58^{*}$ & 1 & & & & \\
$\mathrm{PM}_{10}$ & $0.35^{*}$ & $0.68^{*}$ & $0.69^{*}$ & 1 & & & \\
$\mathrm{SO}_{2}$ & $0.22^{*}$ & $0.62^{*}$ & $0.52^{*}$ & $0.80^{*}$ & 1 & & \\
Minimum temperature & $0.17^{*}$ & $-0.09^{*}$ & $-0.18^{*}$ & $-0.25^{*}$ & $-0.31^{*}$ & 1 & \\
Relative humidity & $-0.36^{*}$ & $-0.34^{*}$ & $-0.30^{*}$ & $-0.50^{*}$ & $-0.44^{*}$ & $0.1^{*}$ & 1
\end{tabular}

${ }^{*} \mathrm{P}<0.05$.

Table 3. Regression coefficients and standard error of the means for cardiovascular emergency room visits by patients with and without diabetes, due to interquartile range increases in air pollutants.

\begin{tabular}{|c|c|c|c|c|c|}
\hline \multirow[t]{3}{*}{ Pollutants } & \multicolumn{5}{|c|}{ Regression parameters and pollutants IQR } \\
\hline & \multicolumn{2}{|c|}{ CVD/diab } & \multicolumn{2}{|c|}{ CVD/nondiab } & \multirow[t]{2}{*}{ IQR } \\
\hline & Coefficients & SEM & Coefficients & SEM & \\
\hline \multicolumn{6}{|l|}{$\mathrm{CO}$} \\
\hline Concurrent day & 0.0575 & 0.0410 & 0.0286 & 0.0095 & 1.28 ppm \\
\hline Lag 1 & -0.0056 & 0.0418 & 0.0098 & 0.0091 & \\
\hline Lag 2 & -0.0304 & 0.0426 & 0.0102 & 0.0089 & \\
\hline $\mathrm{mm} 2$ & 0.0324 & 0.0470 & 0.0271 & 0.0108 & \\
\hline $\mathrm{mm} 3$ & 0.0074 & 0.0528 & 0.0281 & 0.0120 & \\
\hline $\mathrm{mm} 4$ & -0.0025 & 0.0582 & 0.0306 & 0.0131 & \\
\hline \multicolumn{6}{|l|}{$\mathrm{SO}_{2}$} \\
\hline Concurrent day & 0.0174 & 0.0102 & 0.0085 & 0.0022 & $8.02 \mu \mathrm{g} / \mathrm{m}^{3}$ \\
\hline Lag 1 & 0.0233 & 0.0094 & 0.0028 & 0.0021 & \\
\hline Lag 2 & 0.0096 & 0.0097 & 0.0011 & 0.0021 & \\
\hline $\mathrm{mm} 2$ & 0.0275 & 0.0114 & 0.0079 & 0.0025 & \\
\hline $\mathrm{mm} 3$ & 0.0276 & 0.0126 & 0.0073 & 0.0028 & \\
\hline $\mathrm{mm} 4$ & 0.0223 & 0.0139 & 0.0077 & 0.0031 & \\
\hline \multicolumn{6}{|l|}{$\mathrm{NO}_{2}$} \\
\hline Concurrent day & 0.0025 & 0.0011 & 0.0010 & 0.0003 & $64.22 \mu \mathrm{g} / \mathrm{m}^{3}$ \\
\hline Lag 1 & 0.0017 & 0.0012 & 0.0003 & 0.0003 & \\
\hline Lag 2 & 0.0012 & 0.0012 & 0.0001 & 0.0003 & \\
\hline $\mathrm{mm} 2$ & 0.0028 & 0.0013 & 0.0009 & 0.0003 & \\
\hline $\mathrm{mm} 3$ & 0.0029 & 0.0015 & 0.0009 & 0.0003 & \\
\hline $\mathrm{mm} 4$ & 0.0022 & 0.0016 & 0.0008 & 0.0004 & \\
\hline \multicolumn{6}{|l|}{$\mathrm{PM}_{10}$} \\
\hline Concurrent day & 0.0010 & 0.0028 & 0.0010 & 0.0006 & $28.07 \mu \mathrm{g} / \mathrm{m}^{3}$ \\
\hline Lag 1 & -0.0014 & 0.0026 & 0.0003 & 0.0005 & \\
\hline Lag 2 & -0.0004 & 0.0025 & 0.0002 & 0.0005 & \\
\hline $\mathrm{mm} 2$ & -0.0004 & 0.0030 & 0.0008 & 0.0006 & \\
\hline $\mathrm{mm} 3$ & -0.0006 & 0.0032 & 0.0007 & 0.0007 & \\
\hline $\mathrm{mm} 4$ & -0.0024 & 0.0035 & 0.0008 & 0.0008 & \\
\hline \multicolumn{6}{|l|}{$\mathrm{O}_{3}$} \\
\hline Concurrent day & 0.0004 & 0.0012 & 0.0000 & 0.0003 & $53.34 \mu \mathrm{g} / \mathrm{m}^{3}$ \\
\hline Lag 1 & -0.0001 & 0.0012 & -0.0001 & 0.0003 & \\
\hline Lag 2 & 0.0014 & 0.0011 & -0.0001 & 0.0003 & \\
\hline $\mathrm{mm} 2$ & 0.0002 & 0.0014 & -0.0001 & 0.0003 & \\
\hline $\mathrm{mm} 3$ & 0.0009 & 0.0015 & -0.0001 & 0.0004 & \\
\hline $\mathrm{mm} 4$ & 0.0010 & 0.0016 & -0.0001 & 0.0004 & \\
\hline
\end{tabular}

$\mathrm{CVD} /$ diab $=$ cardiovascular disease in diabetic patients; $\mathrm{CVD} /$ nondiab $=$ cardiovascular disease in non-diabetic patients; IQR = interquartile range; Concurrent day = lag 0; Lag 1 and $2=$ values of the previous daily pollutants according to daily emergency room visits; $\mathrm{mm}=$ 2-, 3-, and 4-day moving average. Values in bold indicate significant association between air pollutant and outcome. 
cardiovascular ER visits of diabetic and non-diabetic patients, peaking during wintertime. The ozone pattern was unique among pollutants, with peaks usually during summertime with eventual high levels in wintertime. Wintertime is usually dryer than summertime and warm as well.

Pearson correlation coefficients (Table 2) showed high, positive and statistically significant correlations between primary pollutants. As expected, all of them presented negative associations with temperature and humidity. Ozone was positively associated with primary pollutants and temperature, reflecting that its formation requires both, i.e., nitrogen dioxide and sunlight as precursors.

Table 3 shows the regression coefficients and standard error of the means in cardiovascular ER visits by patients with and without diabetes. Sulfur dioxide and $\mathrm{NO}_{2}$ presented positive and statistically significant associations with both outcomes. These effects were predominately acute (lag 0 and lag 1 ). Carbon monoxide presented an acute and statistically significant effect exclusively for non-diabetic patients. $\mathrm{PM}_{10}$ and $\mathrm{O}_{3}$ did not present significant effects on their results.

Figure 2 shows percentage increases and $95 \% \mathrm{Cl}$ in cardiovascular ER visits of patients with and without diabetes due to interquartile range increases in $\mathrm{CO}, \mathrm{SO}_{2}$, and $\mathrm{NO}_{2}$ levels. Sulfur and nitrogen dioxide effects presented similar patterns and magnitude. From concurrent day to lag 2 and due to moving averages, effects among diabetic patients were 2- to 4-fold those observed among nondiabetic ones. Carbon monoxide effect in non-diabetics presented similar lag pattern to those observed for $\mathrm{NO}_{2}$ and $\mathrm{SO}_{2}$.

\section{Discussion}

We investigated whether the effects of air pollutants on cardiovascular diseases are modified by diabetes mellitus. This hypothesis was presented by Zanobetti and Schwartz (8) who showed increases in cardiovascular admissions associated with diabetes. They observed that, among diabetics, the risk of hospital admissions for heart diseases is 2-fold greater than that observed for non-diabetic individuals.

Our study showed an acute and positive association between $\mathrm{NO}_{2}, \mathrm{SO}_{2}, \mathrm{CO}$ and daily cardiovascular $\mathrm{ER}$ visits for non-diabetic individuals, with increases ranging from 4 to $6 \%$ per each observed interquartile increase.

Increases in daily $\mathrm{NO}_{2}$ concentrations have been associated with increased cardiovascular admissions in several studies (13-15). CO has also been associated with admissions for cardiovascular events (16-19). Martins and colleagues (20) showed a significant association between elderly patient hospital admissions due to cardiovascular diseases and $\mathrm{SO}_{2}$ in São Paulo, Brazil. This effect varied in degree by gender, being greater in females.

Although the number of daily cardiovascular ER visits by diabetics was not high, in the present study, the strong and significant statistical effects of atmospheric $\mathrm{SO}_{2}$ and $\mathrm{NO}_{2}$ concentrations were consistent with the view that diabetes potentiates the effect of air pollutants on cardiovascular disease.

Goldberg and colleagues (21) also reached similar

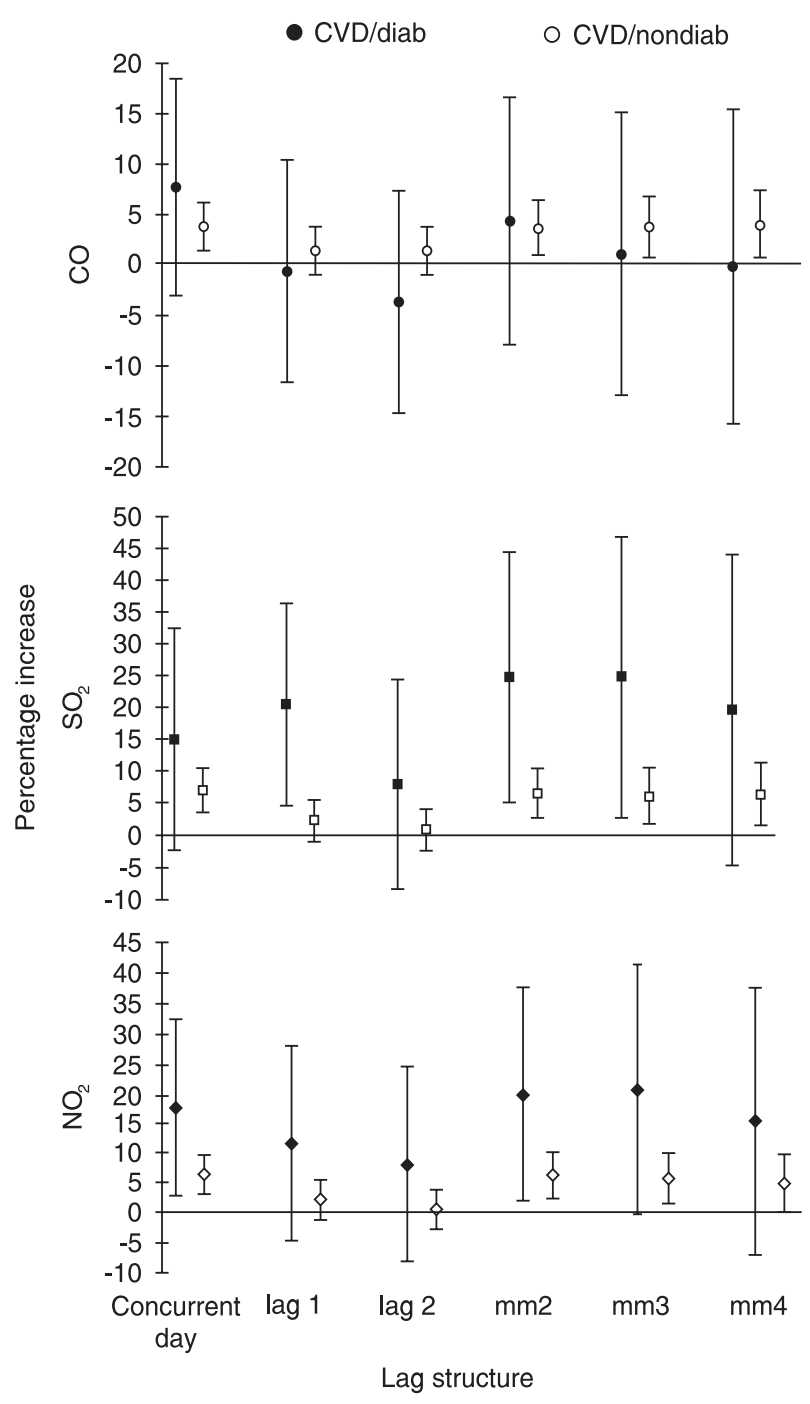

Figure 2. Increases (\%) and 95\% confidence level intervals of cardiovascular emergency room visits by diabetic (CVD/diab, open symbols) and nondiabetic (CVD/nondiab, closed symbols) individuals due to interquartile range increases in $\mathrm{CO}(1.2 \mathrm{ppm})$, $\mathrm{SO}_{2}\left(8.0 \mu \mathrm{g} / \mathrm{m}^{3}\right)$, and $\mathrm{NO}_{2}\left(64.3 \mu \mathrm{g} / \mathrm{m}^{3}\right)$. Concurrent day = lag 0 ; Lag 1 and 2 = values of the previous daily pollutants according to daily emergency room visits; $\mathrm{mm}=2-$, 3-, and 4-day moving average. 
results thus indicating that diabetics with cardiovascular disease may be more susceptible to short-term effects of air pollution. The results of our study corroborate these findings showing a 3-fold increase on morbidity index in the diabetic group.

Utell and colleagues (22) suggest that imbalance of the autonomic nervous system, alterations on ion channel function in myocardial cells, ischemic responses in the myocardium, and inflammatory responses triggering endothelial dysfunction, atherosclerosis, and thrombosis may be involved in the pathophysiology of adverse cardiovascular effects of fine particulate matter.

Although these hypotheses were developed to explain cardiovascular morbidity and mortality associated with particulate air pollution, similar mechanisms might as well apply to both $\mathrm{CO}$ and $\mathrm{NO}_{2}$ (23). Both experimental (24) and epidemiological studies $(25,26)$ have linked $\mathrm{CO}, \mathrm{SO}_{2}$, and $\mathrm{NO}_{2}$ to cardiovascular diseases.

Allred and colleagues (27) pointed out an increase in carboxyhemoglobin levels in response to 8-h average 9ppm CO concentrations when evaluated by time to onset of exercise-induced angina and shorter ST intervals among nonsmoking volunteers with ischemic heart diseases.

It is currently assumed that type 2 diabetes mellitus is associated with impaired endothelial synthesis of nitric oxide and that this might explain, at least in part, the increased cardiovascular risk associated with this condition (28). Endothelial dysfunction contributes to hypertension buildup, arteriosclerosis, and coronary artery disease characterized by resistance to insulin (29). Exposure to urban air pollution also causes inflammatory responses being associated with the progression of arteriosclerosis and increased cardiovascular mortality. Macrophages play a key role in arteriogenesis by releasing pro-inflammatory cytokines and forming foam cells in sub-endothelial lesions (30).

Two studies published by O'Neil and colleagues $(31,32)$ strengthen the results of epidemiological investigations like ours. The first one (31), involving 270 inhabitants of Boston, MA, USA, evaluated vascular reactivity among diabetic individuals and those with glucose intolerance. In patients with type 2 diabetes, an association between reduced endothelium-dependent flow-mediated and nitroglycerin-mediated dilations and sulfate particle $\left(\mathrm{SO}_{4}^{-2}\right)$ was found. This suggests that air pollution exposure may be associated with low coronary flow rate thus increasing the risk of coronary occlusion in diabetic patients. The other study by O'Neil (32) showed associations between air pollutants and plasmatic levels of intercellular adhesion molecule 1, vascular cell adhesion molecule 1 and von Willebrand factor in type 2 diabetic patients. These markers of inflammation are involved in thrombotic pathways and are indicators of both damage and dysfunction of the endothelium.

Based on the results of this study, we conclude that the effects of air pollution on cardiovascular ER visits among diabetes patients are greater than the effects observed among those without diabetes.

\section{References}

1. Morris RD. Airborne particulates and hospital admissions for cardiovascular disease: a quantitative review of the evidence. Environ Health Perspect 2001; 109 (Suppl 4): 495500.

2. Committee of the Environmental and Occupational Health Assembly of the American Thoracic Society. Health effects of outdoor air pollution. Part 2. Am J Respir Crit Care Med 1996; 153: 477-498.

3. Pope CA III, Dockery DW. Health effects of fine particulate air pollution: lines that connect. J Air Waste Manag Assoc 2006; 56: 709-742.

4. Braga AL, Zanobetti A, Schwartz J. The lag structure between particulate air pollution and respiratory and cardiovascular deaths in 10 US cities. J Occup Environ Med 2001; 43: 927-933.

5. Brunekreef B, Holgate ST. Air pollution and health. Lancet 2002; 360: 1233-1242.

6. Lin CA, Amador Pereira LA, de Souza Conceição GM, Kishi HS, Milani R Jr, Ferreira Braga AL, et al. Association between air pollution and ischemic cardiovascular emergency room visits. Environ Res 2003; 92: 57-63.

7. de Paula Santos U, Braga AL, Giorgi DM, Pereira LA, Grupi $\mathrm{CJ}$, Lin CA, et al. Effects of air pollution on blood pressure and heart rate variability: a panel study of vehicular traffic controllers in the city of São Paulo, Brazil. Eur Heart J 2005; 26: $193-200$.

8. Zanobetti A, Schwartz J. Are diabetics more susceptible to the health effects of airborne particles? Am J Respir Crit Care Med 2001; 164: 831-833.

9. World Health Organization. ICD-10, International Statistical Classification of Diseases and Related Health Problems. 10th revision. http://www.who.int/classifications/icd/en/. Accessed April 6, 2008.

10. McCullagh P, Nelder JA. Generalized linear models. 2nd edn. London: Chapman and Hall; 1989.

11. Green PJ, Silverman BW. Non-parametric regression and generalized linear models. A roughness penalty approach. London: Chapman and Hall; 1994.

12. Akaike $\mathrm{H}$. Information theory and an extension of the maximum likelihood principal. Budapest: Akademiai Kiado; 1973. 
p 267-281.

13. von Klot S, Peters A, Aalto $P$, Bellander $T$, Berglind $N$ D'Ippoliti $\mathrm{D}$, et al. Ambient air pollution is associated with increased risk of hospital cardiac readmissions of myocardial infarction survivors in five European cities. Circulation 2005; 112: 3073-3079.

14. Linn WS, Szlachcic Y, Gong H Jr, Kinney PL, Berhane KT. Air pollution and daily hospital admissions in metropolitan Los Angeles. Environ Health Perspect 2000; 108: 427-434.

15. Ye F, Piver WT, Ando M, Portier CJ. Effects of temperature and air pollutants on cardiovascular and respiratory diseases for males and females older than 65 years of age in Tokyo, July and August 1980-1995. Environ Health Perspect 2001; 109: 355-359.

16. Burnett RT, Dales RE, Brook JR, Raizenne ME, Krewski D. Association between ambient carbon monoxide levels and hospitalizations for congestive heart failure in the elderly in 10 Canadian cities. Epidemiology 1997; 8: 162-167.

17. Morris RD, Naumova EN. Carbon monoxide and hospital admissions for congestive heart failure: evidence of an increased effect at low temperatures. Environ Health Perspect 1998; 106: 649-653.

18. Morris RD, Naumova EN, Munasinghe RL. Ambient air pollution and hospitalization for congestive heart failure among elderly people in seven large US cities. Am J Public Health 1995; 85: 1361-1365.

19. Schwartz J, Morris R. Air pollution and hospital admissions for cardiovascular disease in Detroit, Michigan. $A m \mathrm{~J}$ Epidemiol 1995; 142: 23-35.

20. Martins LC, Pereira LA, Lin CA, Santos UP, Prioli G, Luiz Odo $C$, et al. The effects of air pollution on cardiovascular diseases: lag structures. Rev Saúde Pública 2006; 40: 677683.

21. Goldberg MS, Burnett RT, Yale JF, Valois MF, Brook JR. Associations between ambient air pollution and daily mortality among persons with diabetes and cardiovascular disease. Environ Res 2006; 100: 255-267.

22. Utell MJ, Frampton MW, Zareba W, Devlin RB, Cascio WE. Cardiovascular effects associated with air pollution: potential mechanisms and methods of testing. Inhal Toxicol 2002; 14: 1231-1247.

23. Mann JK, Tager IB, Lurmann F, Segal M, Quesenberry CP
Jr, Lugg MM, et al. Air pollution and hospital admissions for ischemic heart disease in persons with congestive heart failure or arrhythmia. Environ Health Perspect 2002; 110: 1247-1252.

24. Jeffrey PK. Effects of cigarette smoke and air pollutants on the lower respiratory tract. In: Holgate S, Samet J, Koren $\mathrm{H}$, Maynard R (Editors), Air pollution and health. San Diego: Academic Press; 1999. p 219-268.

25. Peters A, Doring A, Wichmann HE, Koenig W. Increased plasma viscosity during an air pollution episode: a link to mortality? Lancet 1997; 349: 1582-1587.

26. Pekkanen J, Brunner EJ, Anderson HR, Tiittanen P, Atkinson RW. Daily concentrations of air pollution and plasma fibrinogen in London. Occup Environ Med 2000; 57: 818822.

27. Allred EN, Bleecker ER, Chaitman BR, Dahms TE, Gottlieb SO, Hackney JD, et al. Acute effects of carbon monoxide exposure on individuals with coronary artery disease. Res Rep Health Eff Inst 1989; 25: 1-79.

28. Henry RM, Ferreira I, Kostense PJ, Dekker JM, Nijpels G, Heine RJ, et al. Type 2 diabetes is associated with impaired endothelium-dependent, flow-mediated dilation, but impaired glucose metabolism is not; The Hoorn Study. Atherosclerosis 2004; 174: 49-56.

29. Kim JA, Montagnani M, Koh KK, Quon MJ. Reciprocal relationships between insulin resistance and endothelial dysfunction: molecular and pathophysiological mechanisms. Circulation 2006; 113: 1888-1904.

30. Vogel CF, Sciullo E, Wong P, Kuzmicky P, Kado N, Matsumura $\mathrm{F}$. Induction of proinflammatory cytokines and C-reactive protein in human macrophage cell line U937 exposed to air pollution particulates. Environ Health Perspect 2005; 113: 1536-1541.

31. O'Neill MS, Veves A, Zanobetti A, Sarnat JA, Gold DR, Economides PA, et al. Diabetes enhances vulnerability to particulate air pollution-associated impairment in vascular reactivity and endothelial function. Circulation 2005; 111 : 2913-2920.

32. O'Neill MS, Veves A, Sarnat JA, Zanobetti A, Gold DR, Economides PA, et al. Air pollution and inflammation in type 2 diabetes: a mechanism for susceptibility. Occup Environ Med 2007; 64: 373-379. 